\title{
MICROCLIMATIC MONITORING FOR THE ENVIRONMENTAL RISK ASSESSMENT OF THE CAPILLA MAYOR, SANTIAGO DE COMPOSTELA CATHEDRAL (SPAIN)
}

\author{
Bernardi, A. ${ }^{1}$, Becherini, F..$^{*}$, Vivarelli, A. ${ }^{1}$, Pockelè, L. ${ }^{2}$ \& De Grandi, S. ${ }^{2}$ \\ ${ }^{1}$ Institute of Atmospheric Sciences and Climate, National Research Council, Padova, Italy \\ ${ }^{2}$ R.E.D., Padova, Italy \\ E-mail: f.becherini@isac.cnr.it
}

\begin{abstract}
The study of the microclimate is a fundamental prerequisite of cultural heritage restoration strategy, as the durability of the interventions strongly depends on the environmental conditions. Before the restoration of the frescoes of the apse, seriously degraded, the microclimate in the Capilla Mayor of the Santiago de Compostela Cathedral was monitored continuously for one year to assess the main environmental risks and elaborate a preventive conservation plan. The main natural and anthropic factors affecting the microclimate of the Capilla were identified, as well as their relevance and the associated risk of damage to the frescoes. In particular, the thermo-hygrometric values measured close to the vault were not fully in compliance with respect to the ranges indicated in literature for the conservation of the frescoes. Finally, solutions were suggested to improve the environmental conditions in the Capilla, thus reducing further damage and enhancing the durability of the frescoes after the planned restoration.
\end{abstract}

Keywords: Microclimatic monitoring, Environmental risk assessment, Preventive conservation, Historical building management, Conservation strategy

\section{Introduction}

The microclimatic monitoring is a useful tool in environmental diagnostics and is absolutely necessary for the progress of the knowledge on the basic processes affecting cultural heritage, evidencing causes, effects and deterioration mechanisms [1]. An environment devoted to the display and/or conservation of works of art should have microclimatic conditions as stable as possible, included within the range recommended for each material reported in the standards [2,3]. In addition, in case of hygroscopic organic materials the "historic climate" should be respected, because remarkable changes and discontinuities would be noxious for conse- rvation [4]. Any environmental perturbation, including those related to the management of a building, such as the operation of HVAC and illumination systems, the opening of doors and windows, the presence of visitors, and so forth, can contribute to the deterioration of the works of art, often with irreversible consequences [5]. Churches constitute an inestimable wealth composed of sacred and liturgical items, not less than the patrimony preserved in museums. As all the ancient buildings, churches are intrinsically suitable for conservation, because of their structure and the general absence of HVAC systems [6]. Nevertheless, an 
incorrect management can cause damage to the works of art, whose quantity, quality and variety in a church is enormous. The domed apse is almost always the heart of the church, because of its cultural, symbolic and sacred value, and its vault is very often a masterpiece of frescoes $[7,8]$ and decorations, hence it should be clearly viewed and fully enjoyed by the visitors. The evaluation of the compatibility between the microclimatic conditions of a building, its climate control potential and the conservation requirements of the works of art is very important $[1,6]$. Nevertheless, many heritage buildings, such as churches, are not equipped with sophisticated control systems, hence the investigation of the environmental dynamics is necessary for the development of a preventive conservation strategy, that should not be reduced to the setting of the required thermo-hygrometric (T-RH) values. Several indexes ("performance index" or "thermal-hygrometer environmental stress index") have been defined in literature $[9,10]$ to verify the capability of the microclimate control system of a

\section{Research aims}

The microclimatic monitoring of the Capilla Mayor of the Santiago de Compostela Cathedral (Spain) was performed within the "Santiago de Compostela Cathedral Program" (20062012). This multidisciplinary project was financed by the Foundation Pedro Barrié de la Maza, and it was aimed at assessing the microclimatic conditions in the Capilla, identifying at the same time the main environmental factors affecting the state of conservation of the frescoes, in order to develop a preventive conservation strategy and to contribute to the future restoration plan $[13,14]$. In the present paper only the results related to the microclimatic monitoring are reported and discussed. Hence, the detailed description of the state of conservation of the frescoes, as well as the results of the chemical and biological investigations are out of the topic of this paper and can be found elsewhere [15]. museum to keep the thermo-hygrometric parameters at the desired values or to assess the optimal or warning environmental conditions. These indexes are based on the statistical analysis of the T-RH measured values in relation to the recommended ranges [2,3] and they can hardly be translated into mitigation actions, especially for the heritage buildings not equipped with microclimatic control systems. Instead, a risk management approach can provide a decision-making method for the preventive conservation of cultural heritage [11]. The starting point of this approach is the identification of all risks to objects or collections and to assess the magnitude of each risk $[11,12]$. This is not a simple exercise, as the information on the magnitude of many risks is lacking in literature and as the overall risk is a combination of all the individual risks. Anyhow a semi-quantitative application of risk management procedure will lead to better decision on preventive conservation issues.

Before the starting of the restoration works, the thermo-hygrometric conditions of the air close to the frescoes of the dome, in the matroneo and in the apse, the surface temperature of the frescoes and the air velocity in the Capilla were investigated continuously for one year [13]. The data collected were analyzed following three main aims:

1) Evaluate the quality of the thermohygrometric conditions in relation to the recommended values for the frescoes;

2) Assess the main environmental factors representing a risk for the conservation of the frescoes and their relevance;

3) Suggest mitigation actions to be included in the preventive conservation plan in order to improve the microclimatic conditions for the future maintenance of the Capilla.

These topics were further developed following a risk management approach to be applied to the whole cathedral. 


\section{Description of the Case Study}

The old city of Santiago de Compostela is included in the UNESCO World Heritage Site since 1885 and the Cathedral, one of the main destinations of pilgrimage since the Middle Ages, was declared Heritage of Cultural Interest in 1896. The Capilla Mayor can be considered the heart of the Cathedral. An enormous gilt wood baldachin, with a sumptuous carved stone statue of Saint James from the $13^{\text {th }}$ century, rises above the main altar, fig. (1-a). The choir is covered by three bays and surrounded with an ambulatory and five radiating

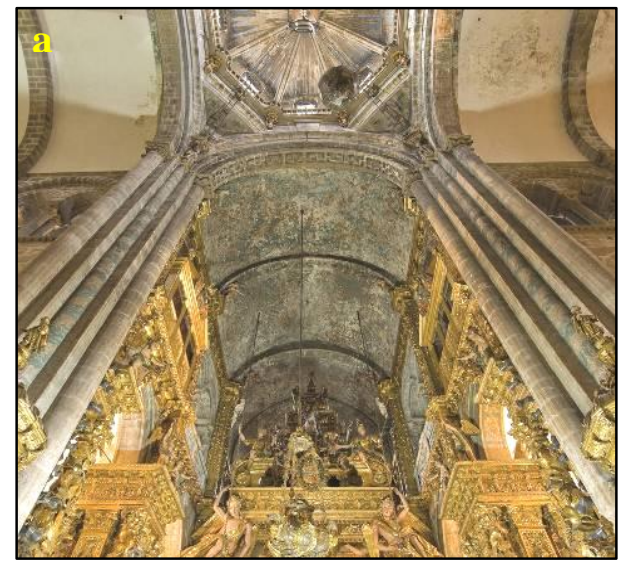

chapels. The vault of the apse is pierced by round windows, forming a clerestory, that give light and fresh air to the matroneo. The frescoes of the dome were realized between 1764 and 1766 by Gabriel Fernàndez; on a blue background, probably representing the sky, putti and angels dance holding symbols of Christ's Passion. At today the painted surface shows a remarkable weathering: decohesion, pulverization, detachment, loss of fragments of material, craquelure and fractures make its viewing extremely difficult, fig. (1-b) [15].

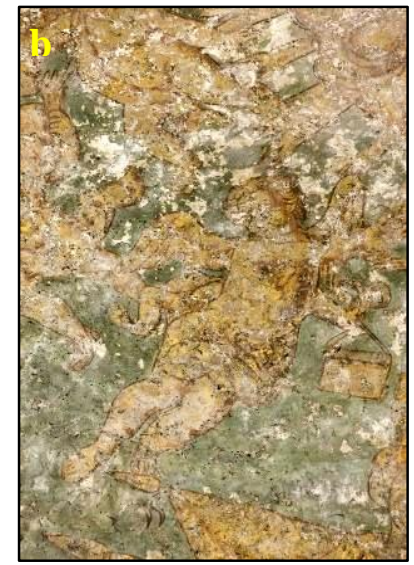

Figure (1) Shows the Capilla Mayor: $\underline{\mathbf{a}}$. general overview, $\underline{\mathbf{b}}$. close views of the frescoes of the apse vault heavily deteriorated

\section{Material and Methods}

The microclimate in the Capilla was monitored from January to December 2010, following the methodology described in details in $[1,6]$ that includes automatic monitoring of: i) air temperature (T) and relative humidity $(\mathrm{RH})$ in proximity of the frescoes and few centimeters far from them in three selected points " $1,2,3$ " in fig. (2) differently oriented (north, east and south) to investigate the exchanges between the surface and the internal atm-osphere; ii) the air thermal vertical profile in the apse point " 4 " in fig. (2) at three levels from the floor: high (close to the vault), middle and low (about $2.5 \mathrm{~m}$ ) to evaluate the risk of vertical air movements and cons-equently transport of pollutants towards the dome where they can deposit $[16,17]$, thus contributing to its weathering; iii) surface temperature (Ts) in three selected points of the apse vault differently oriented " $1,2,3$ " in fig. (2) to monitor the thermal behaviour in different orientations (north, east and south) and evaluate the risk of condensation; iv) anemometric measurements in the same three points " $1,2,3$ " in fig. (2) to control the air velocity close to the frescoes. In order to have a more complete picture of the microclimate, the monitoring program included also manual campaigns [6] to be performed for few days in the four seasons to investigate the thermo-hygrometric horizontal distribution at the level of the matroneo, fig (2). Air temperature and relative humidity were also collected automatically outside the Capilla to study the influence of the external climatology and the exchanges indoors/outdoors through the windows located in the external perimeter 
of the matroneo. Due to the difficulties in the signal transmission, a wired system was preferred to a wireless system for the continuous monitoring of air and surface temperatures (platinum thermo resistances, accuracy respectively $\pm 0.2^{\circ} \mathrm{C}$ and $\pm 0.1^{\circ} \mathrm{C}$ ), relative humidity (capacitive sensors, accuracy $\pm 3 \%$ ) and wind velocity (hot wire anemometers, accuracy \pm 0.05 $\mathrm{m} / \mathrm{s}$ ), fig. (3). The risk of superficial condensation was evaluated with calculations but its presence on the surface was also measured directly with an innovative dew sensor [18]. Air T and RH very close to the vault surface were measured with a psychrometer specifically built $( \pm$ accuracy $\pm 0.01{ }^{\circ} \mathrm{C}$ and $\pm 3 \% \mathrm{RH}$ ), fig. (3). All the sensors were connected to a central PC where the management software of the monitoring network and the data trans-mission software were running. The data were collected every 20 minutes and they were stored locally on the central PC configured for remote access. The sensors were calibrated prior to their installation. During few days of each season $\mathrm{T}$ and $\mathrm{RH}$ were manually monitored every 3-4 hours in a horizontal cross section $(1.5 \mathrm{~m}$ above the floor) of the matroneo, based on about 30 sampling points from each section. These measurements were performed with a fastresponse psychrometer (accuracy $0.1^{\circ} \mathrm{C}$ and $3 \% \mathrm{RH}$ ) that was displaced from each point to the next one, in order to monitor spatial gradients, exchanges between atmosphere and walls, spatial patterns of air masses with different thermo-hygrometric characteristics $[1,6]$. The description of further details on the experimental apparatus and the monitoring campaign can be found in the final report drawn up for the Foundation [13].

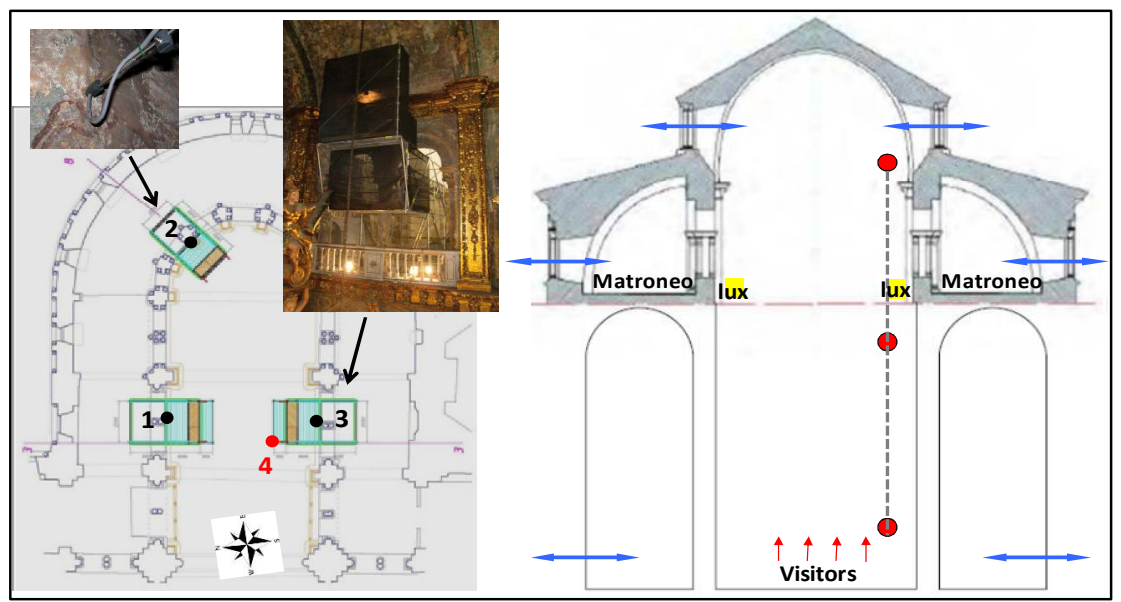

Figure (2) Shows a. horizontal (at the height of the matroneo), $\underline{\mathbf{b}}$. vertical (south-north axis) sections of the Capilla with the indication of the monitoring points in correspondence of the three scaffoldings installed for the investigations.
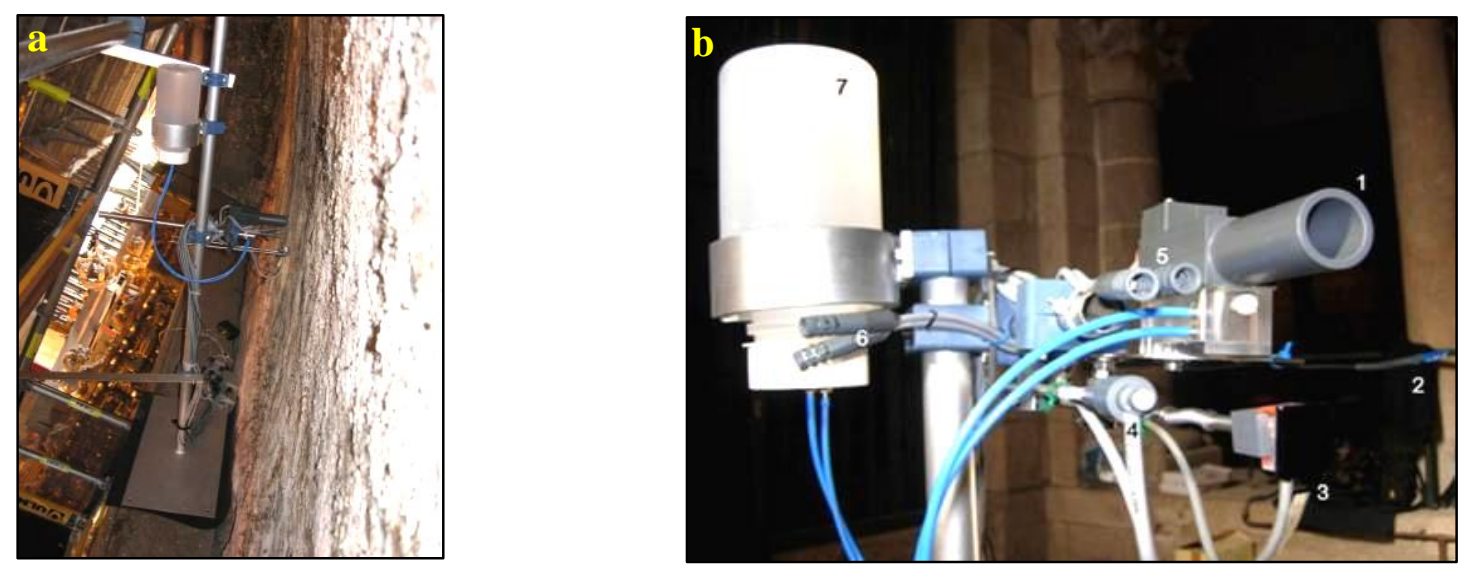

Figure (3) Shows equipment for microclimatic monitoring a $\underline{\mathbf{a}}$. installed close to the apse vault, $\underline{\mathbf{b}}$. close view of the instruments: psycrometer $\mathbf{1}$, anemometer $\mathbf{2}$, dew sensor $\mathbf{3}$, contact temperature sensor $\mathbf{4}$, air temperature and relative humidity sensors $5 \& \mathbf{6}$, water reservoir for the psycrometer 7. 


\section{Results}

The elaboration of the data put in evidence that the microclimate inside the Capilla was strongly influenced by the external climatology notwithstanding its high heat capacity and large thermal inertia. In fact, the temporal trend of the thermo-hygrometric levels inside the Capilla followed the external values, with variations reduced in amplitude. The temperature inside was higher than outside $\left(2-4^{\circ} \mathrm{C}\right.$ on average depending on the month), influencing the indoor relative humidity that resulted $10-20 \%$ lower than outside. The impact of the external climate was also evident from the analysis of the data collected during the manual measurements in the matroneo. In general, the thermal minima were measured in proximity of the north and east walls, whilst the south wall was characterized by the maxima. In fact, the windows are located alongside the perimeter of the matroneo, except for the most part of the south side. In each season the thermal horizontal distribution showed the entrance of colder air from the open slots at the bottom of the windows that were sometimes left partially open, fig. (4) for the air exchange inside the cathedral. The manual measurements showed also the impact of the lamps located in the internal perimeter of the matroneo, especially the one in correspondence of the north scaffolding. The heating due to their operation during the opening hours of the cathedral was clearly visible in the thermal horizontal distributions characterized by thermal maxima nearby the light sources. At the same time, a rise in the air temperature measured close to the vault and of the surface temperature of the frescoes was detected. An example of the perturbing action of the lamps is shown in fig. (4), where an increase of about $1{ }^{\circ} \mathrm{C}$ in air temperature and of about $0.5^{\circ} \mathrm{C}$ in surface temperature was detected in 1 hour on the $17^{\text {th }}$ Feb. 2010.
The analysis of the thermal vertical profile in the apse showed a $1-2{ }^{\circ} \mathrm{C}$ increase of air temperature during the masses due both to the operation of the lamps and to the presence of a huge number of people that remarkably perturbed the internal microclimatic conditions of the whole cathedral, especially during the holidays when it is overcrowded (i.e., Saint James, at the end of July, is very popular). In particular, in spring and summer when this increase in air temperature occurred, e.g., during the masses, the more general conditions of atmospheric stability turned to instability [16]. This means air vertical movements and risk of aerodynamic deposition [17] of pollutants on the surfaces, especially between the high and middle levels, fig. (5). On the contrary, independently from the moment of the day, in winter and autumn the stratification of air masses created two different air circulations closed at the middle level: between the low and middle levels the thermal vertical profile was always stable, unstable between the middle and high levels. Conditions of instability were also favoured by the vault not properly insulated that contributed to cool down the temperature of the air in its proximity. The atmospheric stability between the low and middle levels inhibited the transport towards the dome of the pollutants that entered the cathedral through the doors or that were brought in by the visitors. Hence, the presence of visitors in the currently allowed areas of the cathedral didn't enhance the risk of deposition of pollutants on the frescoes. Nevertheless, the atmospheric instability between the middle and high levels favoured the resuspension and the aerodynamic deposition of the pollutants previously settled on the wood baldachin, always covered by dust [17]. The air velocity close to the apse vault reached its highest values in the middle of the 
day (up to $40 \mathrm{~cm} / \mathrm{sec}$ in summer, to $30-35$ $\mathrm{cm} / \mathrm{sec}$ in the other seasons), in correspondence of the pilgrims' mass, whilst during the night the air movements slowed down. The frequent conditions of atmospheric instability between the high and middle levels and the high air velocity values favoured aerodynamic deposition of micronic particles, that may react with the heritage surfaces under specific microclimatic conditions, in particular in presence of water (condensation on the surface or in the micropores of the material) $[1,6]$. The analysis of the temperature of the internal surface of the apse vault and of the air close to it showed throughout the year that surface temperature was lower than air temperature. This thermal gradient favoured the phenomenon of thermophoretic deposition of submicronic particles (diameter less than $1 \mu \mathrm{m})$, characterized by a greater resident time in atmosphere [17], fig. (4). The analysis of the hygrometric gradients close to the surface indicated that the diffusiophoretic deposition $[1,6,17]$ was on the contrary inhibited in summer and autumn, whilst in the other seasons this phenomenon occurred, acting in synergistic combination with the thermophoretic process. Hence, the two different phoretic processes had synergistic or opposite action, depending on the season and moment of the day. The hygrometric values in the Capilla were generally quite high, with an annual average of $70 \% \mathrm{RH}$ and maxima of $90 \%$ frequently reached in autumn and winter. It is well known that high levels of relative humidity favour biological life $[1,6]$. The threshold hygrometric level depends on the type of species considered, and it is also related to other environmental conditions (e.g., air and surface temperature, equilibrium moisture content, ventilation, air pollution, etc.). Anyhow, in temperate regions, the RH level should prudentially remain below $70 \%$ in order to protect cultural heritage from biological risk [1]. The relative humidity measured close to the vault was higher than $70 \%$ for $42 \%$ of the total time of monitoring ( 1 year): this percentage increases to $63 \%$ if the threshold is lowered to $65 \%$. The samples collected on the surface of the apse vault indicated the presence of different species of microorganisms (i.e., mesophilic aerobic, mould, actinomycete, pseudomonas, algae and cianobacteria) [15], characterized by different levels of activity, that is mainly related to the ventilation. In fact, the higher activity was found in the area characterized by less ventilation. Air humidity and material dampness also favour weathering. Water supplied by condensation causes dissolution of the material matrix; condensation / evaporation cycles cause capillary migration of dissolved salts and crystallization (efflorescence and subflorescence), thus weakening the material and determining both material and aesthetic value loss $[1,6]$. Hence, the risk for superficial condensation was evaluated by the statistical analysis of the difference between surface temperature and air dew point in one year period and it was also measured directly by means of a new dew sensor [18]. Results showed that condensation occurred between late autumn and early spring, with the maximum risk in Jan. and Feb. when the phenomenon was favoured for about the $40 \%$ of time of monitoring, fig. (6). The preliminary results of the chemical analyses performed on the samples collected on the internal surface of the apse vault indicated a porosimetry between $20-30 \%$, with mainly macropores with size in the range $0.1-1 \mathrm{~mm}$ [15]. Hence, even if the high values of air relative humidity indicate also a high risk for condensation inside the micropores of the material, this phenomenon can be considered less relevant than the superficial condensation, being the material and in particular the surface heavy degraded and consequently characterized by pores of big size. 

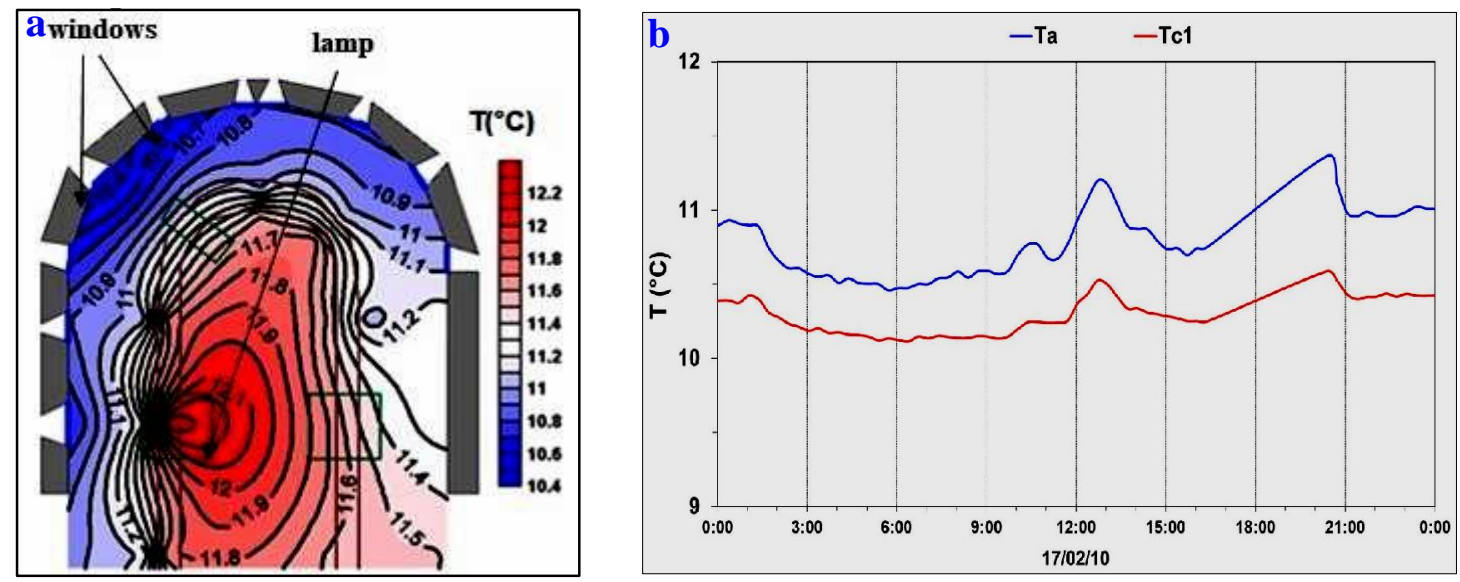

Figure (4) Shows a. thermal horizontal distribution on the 17/02/2010 in the matroneo, $\underline{\mathbf{b}}$. daily trend of the air (Ta) and surface (Tc1) temperature of the vault in the north side in June showing peaks in correspondence to the masses due to the operation of the lamps and the presence of visitors.

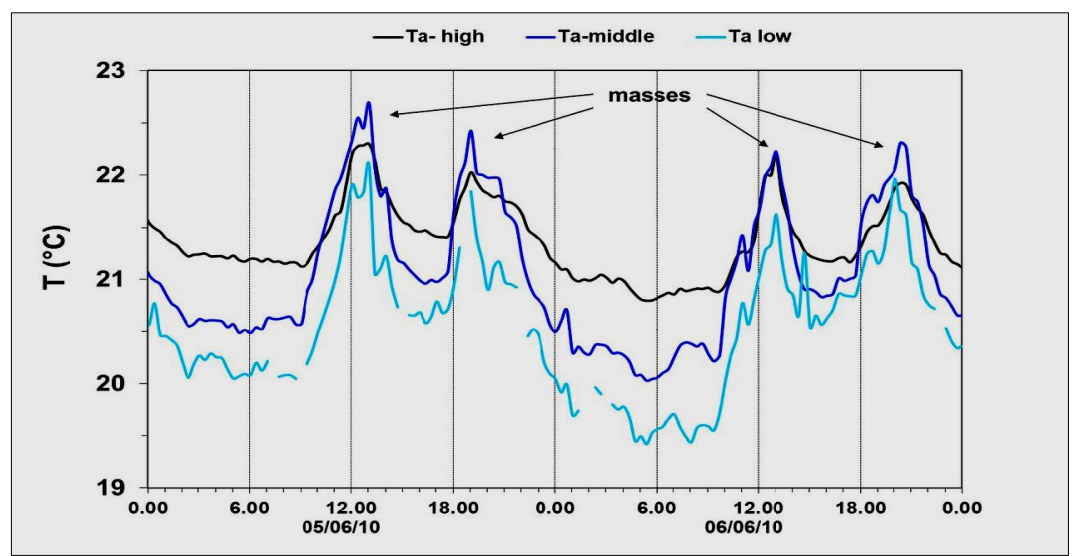

Figure (5) Shows atmospheric instability between the middle and high levels of the air vertical profile in the apse during the masses in late spring.

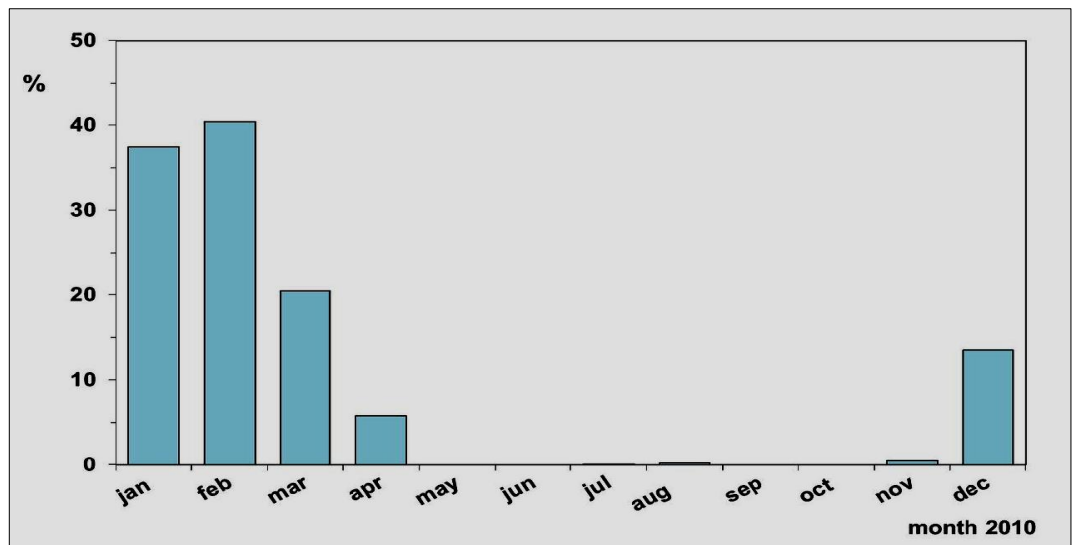

Figure (6) Shows monthly risk of superficial condensation (percentage of total time) for the Capilla.

\section{Discussion}

The research performed allowed the identification and characterization of the main microclimatic phenomena related to the deterioration processes affecting the surface, that are summarized in tab. (1) [2]. The variation of the thermohygrometric conditions of the air and consequently of the materialwere the main responsible for the remarkable weathering phenomena affecting the frescoes of the vault, i.e., decohesion, detachment, loss of fragments of material, fractures, damage. At the same time, changes in the moisture content of the material and condensation phenomena, combined with ventilation, caused notable efflorescence and sub- 
florescences. All these microclimatic phenomena had an important effect on the very critical state of conservation of the frescoes of the Capilla Mayor, hence the risk associated to them can be considered severe. The painted surface was also affected by soiling and biological growth, but the severity of these damage was less compared to the above mentioned ones. Soiling was related to particles deposition processes, mainly diffusiophoresis, thermophoresis and aerodynamic deposition. High relative humidity values, variation of the moisture content of the material, superficial condensation, together with ventilation contributed to the risk for biodeterioration. Then, the main natural and anthropic factors affecting the microclimatic conditions of the Capilla and thus responsible for the damage of the frescoes were identified, as well as with their related importance [2]. These factors are presented in tab. (2). Basically the natural factors, i.e., solar radiation and external climatology, were constant in occurrence, and have a high impact. The importance of the anthropic factors was high too, but their perturbing action was sporadic, being related to the management and use of the Cathedral. Among the anthropic factors, the presence of visitors was the less important one for the Capilla, mainly because of the presence of the big wooden baldachin that acted as a hygrometric buffer. The synergistic action of all the mentioned factors lead to microclimatic conditions that might reduce the durability of the frescoes even after the restoration. In fact, the thermohygrometric reference range for the conservation of the frescoes, reported in the currently approved Italian standard UNI 10829 [5] (i.e. $10-24^{\circ} \mathrm{C}$ for $\mathrm{T}$ and $55-65 \%$ for $\mathrm{RH}$ ), was satisfied only for the $26 \%$ of total time of monitoring. This low percentage was mainly related to $\mathrm{RH}$, whose measured values were almost always over the upper limit of the range, as is clearly visible in fig. (7).

Table (1) Main deterioration processes affecting the frescoes of the Capilla, related microclimatic phenomena and damage level.

\begin{tabular}{|c|c|c|}
\hline Type of damage & Related microclimatic phenomena & $\begin{array}{l}\text { Severity } \\
\text { of effect }\end{array}$ \\
\hline $\begin{array}{l}\text { Decohesion, } \\
\text { Detachment, Loss of mat- } \\
\text { erial, fractures }\end{array}$ & $\begin{array}{l}\text { - Variation of air T-RH } \\
\text { - Variation of surface T }\end{array}$ & Severe \\
\hline $\begin{array}{l}\text { Florescences and } \\
\text { Sub-florescences }\end{array}$ & $\begin{array}{l}\text { - RH cycles } \\
\text { - Variation of the moisture content of the material, condensation } \\
\text { - Ventilation }\end{array}$ & Severe \\
\hline Soiling & $\begin{array}{l}\text { - Diffusiophoretic deposition (air water content) } \\
\text { - Thermophoretic deposition (air and surface T) } \\
\text { - Aerodynamic deposition (ventilation, vertical thermal profile) }\end{array}$ & Mild \\
\hline Biological growth & $\begin{array}{l}\text { - High RH } \\
\text { - Variation of the moisture content of the material } \\
\text { - Superficial condensation } \\
\text { - Ventilation }\end{array}$ & Mild \\
\hline
\end{tabular}

Table (2) Main natural and anthropic factors contributing to the deterioration phenomena in the Capilla and related importance.

\begin{tabular}{|c|c|c|c|}
\hline Main factors of deterioration & Related phenomena & Importance & Comments \\
\hline - External climatology & $\begin{array}{l}\text { - T-RH variations } \\
\text { - Evaporation } \\
\text { - Condensation } \\
\text { - Deposition processes }\end{array}$ & Indirect: High & $\begin{array}{l}\text { Impact of direct solar rad- } \\
\text { iation not present, diffuse } \\
\text { radiation negligible. Indirect } \\
\text { effect remarkable through } \\
\text { the heating of the vault, } \\
\text { not properly insulated. } \\
\text { Indoor microclimate strongly } \\
\text { influenced by the external } \\
\text { climate. }\end{array}$ \\
\hline
\end{tabular}




\begin{tabular}{|c|c|c|c|c|}
\hline \multirow{3}{*}{ 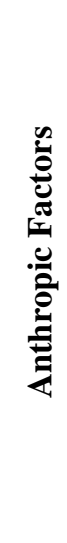 } & - Illumination system & $\begin{array}{l}\text { T-RH variations, depo- } \\
\text { sition processes }\end{array}$ & High & $\begin{array}{l}\text { System characterized by } \\
\text { high dissipation of energy. }\end{array}$ \\
\hline & - Doors and windows & $\begin{array}{l}\text { - T-RH variations } \\
\text { - Deposition processes }\end{array}$ & Medium & $\begin{array}{l}\text { Openings guarantee air } \\
\text { changes, but enhance T-RH } \\
\text { stresses (highest salt conce- } \\
\text { ntration measured close to } \\
\text { the windows). }\end{array}$ \\
\hline & - Visitors & $\begin{array}{l}\text { - T-RH variations } \\
\text { - Deposition processes }\end{array}$ & Low & $\begin{array}{l}\text { This effect is less signif- } \\
\text { icant than others because } \\
\text { of the dimensions of the } \\
\text { Capilla and of the presence } \\
\text { of the big wood baldachin } \\
\text { that acts as a RH buffer. }\end{array}$ \\
\hline
\end{tabular}

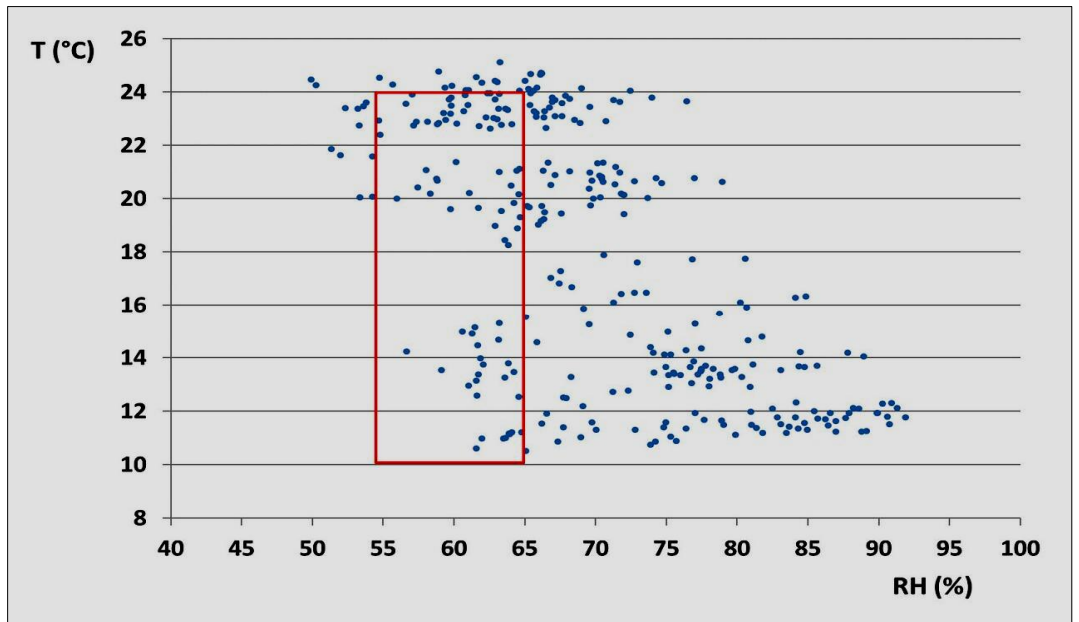

Figure (7) Shows daily average temperature and relative humidity matrix. The square indicates the recommended T-RH range for the frescoes conservation according to the Italian Standard UNI10829.

\section{Conclusion}

In this paper the main results of the microclimatic monitoring for the environmental risk assessment of the Capilla Mayor of the Santiago de Compostela Cathedral (Spain) are discussed. The main natural and anthropic factors affecting the microclimate of the Capilla, their relevance and the associated risk of damage for the frescoes of the apse vault were identified. Moreover, the thermo-hygrometric conditions resulted not in compliance with the ranges indicated in literature for the conservation of the frescoes. The results obtained can be translated in concrete actions to be recommended for the future conservation of the Capilla. The illumination system is one of the main responsible for the atmospheric instability inside the Capilla, hence it is advisable to change the present lamps with ones characterized by lower energy dissipation, taking care of their position, as well as their type of working, continuous or blinking. A lightning-engineering study could be useful to identify the best compromise between the needs of increasing the value of cultural heritage, avoiding at the same time thermal shocks, the formation of convective cells and air motion that could enhance the transport of pollutants and their deposition on the precious surfaces. Indoors, the deposition causes soiling with a bad visual perception that reduces artwork enjoyment. However, visual aesthetics is not the only one affected, because deposited particulate matter constitutes a potential risk for chemical reactions or microbiological infestation. Moreover, as the external climate has a strong influence in the indoor conditions, the improvement of the insulation of the vault can contribute to reduce atmospheric instability, especially in the cold season, and at the same time the thermal gradients between indoors and outdoors. A certain air circulation inside the Capilla should be guaranteed, mainly because of the high hygrometric levels that enhance the risks of condensation and biological life. Hence it is not reasonable to close all the windows, but it is advisable to limit in time and regulate their opening, in order to keep down wind velocity, and to avoid the risk for thermo-hygrometric variations, and consequently of mechanical stresses and salts crystallization/dissolution cycles. The time of opening/closing should be calculated through a careful study and modellisation (fluidodynamic model) of the air exchanges in function of the geometry of the building and the microclimatic conditions. As 
the presence of people has not a remarkable impact on the microclimatic conditions of the Capilla, the reduction of the affluence of visitors in the future it is not crucial for the vault conservation. This solution could have been particularly critical due to the strong attraction of the cultural and religious site. Finally, periodical maintenance should be done, in particular the removal of dust, that is abundant in the whole Cathedral, and that almost totally covers the wood baldachin in the apse, in order to reduce the risk for pollutants deposition on the vault. Moreover, as dust deposits very often create a favourable biological habitat, cleaning is a highly recommended preventive conservation action. The system to be used has to be carefully evaluated, because some common devices (such as traditional vacuum cleaners) cause the resuspension in air of the atmospheric particles already settled, especially the fine ones (diameter lower than $2.5 \mu \mathrm{m}$ ). Hence, instead of reducing the concentration of particles, they generate turbulence and consequently favour aerodynamic deposition.

\section{Acknowledgements}

The authors acknowledge the Archbishop of Santiago, the Cathedral Chapter, the Barrié Foundation, the Regional Ministry of Culture of the Xunta de Galicia and the Technical Direction of the Spanish Institute of Cultural Heritage of the Ministry of Culture, Regional Ministry of Culture of the Xunta de Galicia. The authors would also like to give thanks to Tecnalia and Artelan.

\section{References}

[1] Camuffo, D., (2014). Microclimate for Cultural Heritage, Elsevier, Amsterdam.

[2] UNI-10829, (1999). Beni di interesse storico e artistico, Condizioni ambientali di conservazione, Misurazione ed analisi, Ente Italiano di Normazione, Milano

[3] Ministero per i beni e le attività culturali, D.M. 10.5.2001 (2001). Atto di indirizzo sui criteri tecnicoscientifici e sugli standard di funzionamento e sviluppo dei musei, Italian Minister Degree G.U. n.238, Italy.

[4] EN-15757, (2010). Conservation of cultural property: Specifications for temperature and relative humidity to limit climate-induced mechanical damage in organic hygroscopic materials. European Committee for Standardization, Brussels.

[5] Camuffo, D., Pagan, E., Bernardi, A., Becherini, F., (2004). The impact of heating, lighting and people in reusing historical buildings: A case study, J. of Cultural Heritage, Vol. 5, pp: 409-416

[6] Bernardi, A., (2008). Microclimate inside cultural heritage buildings, II Prato, Il Prato, Padova.

[7] Bernardi, A., Todorov, V., Hiristova, J. (2000). Microclimatic analysis in the St. Stephan church, Nessebar Bulgaria after interventions for the conservation of the frescoes. $J$. of Cultural Heritage, Vol. 1, pp: 281286.

[8] Bernardi, A., Becherini, F., (2006). Evaluation of the microclimatic conditions in the "Vasari Room" aimed at its future exploitation by the public, in: Baldini, U. \& Vigato, P. (eds.) The frescoes of casa Vasari in Florence: An interdisciplinary approach to understanding, conserving, exploiting and promoting, Polistampa, Firenze, pp: 65-79.

[9] Corgnati, S., Fabi, V., Filippi, M., (2009). A methodology for microclimatic quality evaluation in museums: Application to a temporary exhibit. Building and Environment, Vol. 44, pp: 1253-1260.

[10] La Gennusa, M., Rizzo, G., Scaccianoce, G., Nicoletti, F., (2005). Control of indoor environments in heritage buildings: Experimental measurements in an old Italian museum and proposal of a methodology, $J$. of Cultural Heritage, Vol. 6, pp: 147-155.

[11] Becherini, F., Bernardi, A., Vivarelli, A., Pockelé, L., De Grande, S., Gandini, A., García, O., Subyaga, M., Espada Suárez, J., Sperandio, B., (2013). Environmental Risk Assessment and Preventive Conservation Strategy for the Porch of the Glory, Santiago of Compostela Cathedral, $J$. of Environmental Science and Engineering, Vol. B2, pp: 299-303. 
[12] Waller, R., (1995). Risk management applied to preventive conservation, in: Genoway, H., Hawks, C. \& Rose, C. (eds.) Storage of natural history collections: A preventive conservation approach, Society for the preservation of natural history collections, Iowa City, pp: 21-27.

[13] Bernardi, A., Becherini, F., Pockelé, L., De Grandi, S., Gandini, A., García, O., (2001). Final report of the first phase of investigation for the elaboration of the preventive conservation plan: Monitoring of the microclimate in the porch of the glory and in the major chapel of the Santiago of Compostela Cathedral, Scientific report for Pedro Barrié de la Maza Foundation, Pontevedra. (In Spanish).

[14] Bernardi, A., Becherini, F., Pockelé, L., De Grande, S., Gandini, A., García, O., (2011). Monitoring of the environmental and thermo-hygrometric parameters in the major chapel and the porch of the glory of the Santiago of Compostela Cathedral: Strategy of control and management of the environmental risks, Scientific report for Pedro Barrié de la Maza Foundation, Pontevedra. (In Spanish).

[15] Artelan Restauration (2010). Study for the preventive conservation and restoration of the valut and the arches of the major chapel of the Santiago of Compostela Cathedral, Scientific report for Pedro Barrié de la Maza Foundation, Pontevedra. (In Spanish).

[16] Seinfeld, J., Pandis, S., (2006). Atmospheric chemistry and physics, John Wiley \& Sons, New Jersey.

[17] Friedlander, S., (2000). Smoke, dust, and haze: fundamentals of aerosol dynamics, Oxford Univ. Press, NY.

[18] Bernardi, A., Becherini, F., Pockelé, L., De Grandi, S., (2012). Conservation of stained glass windows: An innovative user-friendly portable device coming from the EU-VIDRIO project, J. of Environmental Science and Engineering, Vol. B1, pp: 519526. 